\title{
BMJ Open Possible role of IL-6 and TIE2 gene polymorphisms in predicting the initial high transport status in patients with peritoneal dialysis: an observational study
}

Li Ding, Xinghua Shao, Liou Cao, Wei Fang, Hao Yan, Jiaying Huang, Aiping Gu, Zanzhe Yu, Chaojun Qi, Xinbei Chang, Zhaohui Ni

To cite: Ding L, Shao $X$, Cao L, et al. Possible role of IL-6 and TIE2 gene polymorphisms in predicting the initial high transport status in patients with peritoneal dialysis: an observational study. BMJ Open 2016;6:e012967. doi:10.1136/bmjopen-2016012967

- Prepublication history for this paper is available online. To view these files please visit the journal online (http://dx.doi.org/10.1136/ bmjopen-2016-012967).

LD and XS contributed equally.

Received 14 June 2016 Revised 10 August 2016 Accepted 17 August 2016

CrossMark

Department of Nephrology, Renji Hospital, School of Medicine, Shanghai Jiao Tong University, Shanghai, China

Correspondence to Dr Zhaohui Ni;

nizhaohuibmj@sina.com

\section{ABSTRACT}

Objectives: The aim of this study was to investigate the effect of interleukin (IL)-6 and TIE2 gene polymorphisms on baseline peritoneal transport property.

Design: An observational study.

Setting: Renji Hospital in Shanghai, China.

Participants: This study included 220 patients with continuous ambulatory peritoneal dialysis (PD).

Outcome measures: Patients were divided into 2 groups based on the results of an initial peritoneal equilibration test performed within 3 months of starting PD therapy: group 1 consisted of low/low average transporters ( $n=123)$, and group 2 consisted of high/ high average transporters $(n=97)$. We genotyped TIE2 and IL-6 polymorphisms and analysed their effects on baseline transport status.

Results: The genotype AT in IL-6 Rs13306435 and the genotype CC in TIE2 Rs639225 were both negatively associated with a higher initial peritoneal transport status (IL-6 Rs13306435: OR=0.408, $95 \% \mathrm{Cl}$ 0.227 to 0.736; TIE2 Rs639225: OR $=0.188,95 \% \mathrm{Cl}$ 0.044 to 0.806 ).

Conclusions: IL-6 and TIE2 polymorphisms are associated with baseline peritoneal transport property.

\section{INTRODUCTION}

Peritoneal dialysis (PD) is an effective renal replacement therapy for patients with endstage renal disease (ESRD). ${ }^{1}$ Patients undergoing PD have significantly different small solute transport rates. The standard peritoneal equilibration test (PET) proposed by Twardowski $e t a l^{2}$ in 1987 is the most widely used method to assess the peritoneal small solute transport rate. Patients can be divided into four types: high $(\mathrm{H})$, high average (HA), low average (LA) and low (L) based on PET results. Studies have shown an

\section{Strengths and limitations of this study}

- This study was the first study to explore the possible association between TIE2 gene polymorphisms and the characteristics of peritoneal transport.

- This was also the first study to confirm the association between the interleukin (IL)-6 polymorphism and baseline peritoneal transport among the Chinese Han population.

- We used a convenient and non-invasive method to study the initial high transport status in patients with peritoneal dialysis.

- The TA genotype of rs13306435 present in only $7 \%$ of the total population; therefore, it is not the main determinant of peritoneal transport in most patients.

- We did not examine dialysate IL-6/TIE2 concentration to investigate its relationship with single nucleotide polymorphisms.

association between high transport status and poor outcome. ${ }^{3-6}$ The results of a metaanalysis ${ }^{7}$ have indicated that for every 0.1 increase in the dialysate over plasma ratio for creatinine $(\mathrm{D} / \mathrm{P} \mathrm{Cr})$, the relative risks for mortality and technique failure increase by 1.15 and 1.18, respectively. Compared with the mortality of the low transport group, that of the LA, HA and high transport groups increased by $21.9 \%, 45.7 \%$ and $77.3 \%$, respectively. As technology advances, new peritoneal dialysate (icodextrin) ${ }^{8-11}$ and automated PD (APD) ${ }^{12-14}$ have been shown to improve the prognosis of high transporters. However, in developing countries, icodextrin and APD cannot be widely used for patients with PD. Initial high transport is still an important factor that influences the outcome of these patients without icodextrin 
or APD. Therefore, it is important to know the baseline peritoneal transport property before starting PD therapy. We can advise probable high transporter patients to choose haemodialysis (HD) or renal transplantation for renal replacement therapy. Researchers have attempted to find non-invasive biomarkers to predict the baseline peritoneal membrane function before starting dialysis. Previous studies found that age, gender and complications such as hypertension, diabetes and malnutrition might influence transport characteristics. ${ }^{1}$ However, they are not sufficient to predict high transport status.

In recent years, many studies have shown that genetic variants may play an important role in mechanisms contributing to the baseline variability in peritoneal transport. ${ }^{15-20}$ It has been suggested that chronic inflammation mediated by various inflammatory cytokines may have an effect on peritoneal transport. ${ }^{21}$ Studies have shown that the interleukin (IL)-6 level in peritoneal dialysates is associated with the peritoneal solute transport rate in patients with dialysis. ${ }^{22-24}$ A polymorphism of IL-6 (Rs13306435) is reported to correlate with baseline peritoneal transport status in Caucasian and Korean patients. ${ }^{15} 19$ An increase in the effective solute exchange area caused by peritoneal vascular proliferation is also an important factor for high peritoneal transport status. ${ }^{25}$ TIE2 is the receptor of angiogenin (Ang) 1 and 2. Ang/Tie2 has been confirmed to play an important role in angiogenesis in the peritoneum. ${ }^{26}$ The angiogenesis of the peritoneum induced by PD can be inhibited using sTie2/Fc in a uremic rat model. ${ }^{27}$ Therefore, it is possible that the genetic polymorphisms of IL- 6 and TIE2 might be involved in the mechanism of high peritoneal transport status. This study aimed to determine whether TIE2 and IL-6 gene polymorphisms have an effect on the baseline peritoneal transport property and explore its possible role in predicting initial high transport status.

\section{MATERIALS AND METHODS}

\section{Patient selection}

All patients with PD having an initial PET performed within 3 months of starting PD therapy were included. Those who switched from failed renal allograft or maintenance HD were excluded. Two hundred and twenty patients with continuous ambulatory PD in the Peritoneal Dialysis Center, School of Medicine, in Shanghai Jiaotong University were enrolled in the study.
Written informed consent was obtained from each patient.

\section{Study of peritoneal transport}

A standard PET was performed for each of the enrolled patients. Dialysate as well as plasma creatinine and glucose levels were measured at 4 hours using $2 \mathrm{~L}$ of $2.5 \%$ glucose dialysis fluid. Creatinine dialysate to plasma ratios at 4 hours $(\mathrm{D} / \mathrm{P} \mathrm{Cr})$ were calculated. Patients were classified into four types based on the $\mathrm{D} / \mathrm{P}$ Cr value: $\mathrm{H}(\mathrm{D} / \mathrm{P} \mathrm{Cr}>0.8)$, $\mathrm{HA}(\mathrm{D} / \mathrm{P} \mathrm{Cr} 0.66-0.8)$, LA (D/P Cr 0.5-0.65) and low transporters (D/P Cr $<0.5)$. Then they were divided into two groups: group 1 consisted of L/LA transporters, and group 2 consisted of $\mathrm{H} / \mathrm{HA}$ transporters. The residual urine volume was assessed after 24 hours of urine collection. Weekly peritoneal Kt/V (peritoneal $\mathrm{Kt} / \mathrm{V}$ ) and residual urine $\mathrm{Kt} / \mathrm{V}$ (urine $\mathrm{Kt} / \mathrm{V}$ ) were calculated and presented as total weekly Kt/V (total Kt/V).

\section{DNA extraction and genotyping}

DNA was extracted from whole blood using a DNA purification kit (Promega, USA). The single nucleotide polymorphisms (SNPs) of IL-6 and TIE2 were genotyped by a single base primer extension assay. The genomic DNA flanking the SNP was amplified by PCR using forward and reverse primer pairs (tables 1 and 2), and standard PCR reagents in a $10 \mu \mathrm{L}$ reaction volume containing a $20 \mathrm{ng}$ DNA sample, $0.4 \mu \mathrm{mol}$ of each primer, a $10 \times$ PCR buffer, $0.4 \mu \mathrm{mol}$ dNTPs (Generay Biotech, China), $10 \mathrm{mmol} \mathrm{MgCl}_{2}$ and 0.25 units HotStarTaq DNA Polymerase (QIAGEN, Germany). After 40 cycles of PCR (MJ Research PT-100), the products were purified by $2 \mathrm{U}$ shrimp alkaline phosphatase (SAP) and $2 \mathrm{U}$ exonuclease I (Epicentre). The purified amplification products $(2 \mu \mathrm{L})$ were added into a SNaPShot Multiplex Ready reaction mixture (Applied Biosystems) containing $1 \mu \mathrm{L}$ of genotyping primer for the primer extension reaction (tables 1 and 2). The primer extension reaction was carried out with 25 cycles at $96^{\circ} \mathrm{C}$ for $10 \mathrm{~s}, 50^{\circ} \mathrm{C}$ for $5 \mathrm{~s}$ and $60^{\circ} \mathrm{C}$ for $30 \mathrm{~s}$. The reaction products were purified by $0.5 \mathrm{U}$ $\mathrm{SAP}$. The final reaction samples $(0.5 \mu \mathrm{L})$ were added into 9.25 $\mu \mathrm{L} \mathrm{Hi-Di} \mathrm{formamide} \mathrm{(Applied} \mathrm{Biosystems)} \mathrm{and}$ $0.25 \mu \mathrm{L}$ GS-120 LIZ (Applied Biosystems). The mixture was incubated at $95^{\circ} \mathrm{C}$ for $5 \mathrm{~min}$ and then analysed by electrophoresis using the ABI Prism 3730xl DNA analyser (Applied Biosystems). Results were analysed using GeneScan analysis software (Applied Biosystems).

Table 1 Primer sequences of IL-6 for genotyping using SNapShot assay

\begin{tabular}{llll}
\hline SNP & PCR-L & PCR-R & Target \\
\hline rs1800795 & AACCTCCTCTAAGTGGGCTG & GGTGGGGCTGATTGGAAAC & TCCCCCTAGTTGTGTCTTGC \\
rs1800796 & GAAGGGTCCTACTCAGAGCA & GTTGGGTCAGGGGTGGTTAT & TTCCATTCAGGCAAAGAATCTAGA \\
rs13306435 & GACAGTCTACAACAGCC \\
\hline IL, interleukin; SNP, single nucleotide polymorphism. & &
\end{tabular}


Table 2 Primer sequences of TIE2 for genotyping using the SNapShot assay

\begin{tabular}{llll}
\hline SNP & PCR-L & PCR-R & Target \\
\hline rs10967717 & TTTCCTCTGGTGGGTAGGAA & GGGCTACTGGGATCTCTGAC & GAGGAGTATAATGATTTCCTCAGGC \\
rs657867 & & CCACATGGTTTAATTGGGA \\
rs639225 & TTCTTCCTCCTCAACCAGAAA & TCACATCAACGTGCTGGTCT & CAATATTGTCCAAGAAATCACAGC \\
rs542913 & ACGGGTGGGTCTGTTCTC & GAGGCTTGCCTAAGGGAAAT & CATTCTCCTTTGCACATTTGC \\
rs3737188 & GATTGTCCCGAGGTCAAGAG & TTTCCCAGGGCACACAGTAT & TTGTCCCGAGGTCAAGAGGTGTA \\
rs2273719 & TGGCACTGTTTGTTCCAG & ACCGGCTGACTTTGCTAGAG & AGGCACACCCTACTGCGG \\
rs2273718 & & & AGTCTGTAGCCCTGGGGCA \\
rs10967789 & ATGGGCTGAAATCAGAATGC & AACCTGTACTATCAGGGTCATTG & AATGCTATTAAATGTTTCCTGTGT \\
rs9987817 & CTGGGTGACATTTGGGAGAC & CACTCCTGGATGAGACGTGA & GATGAGACGTGAGTAGGCAAGA \\
\hline SNP, single nucleotide polymorphism. & &
\end{tabular}

\section{Statistical analysis}

Statistical analysis was conducted using SPSS V.17.0. All categorical data were presented as absolute counts or percentages, and mean and SD were provided for continuous data. To compare the differences between two baseline transport groups, categorical data were analysed by Fisher's exact test and continuous variables were analysed by an unpaired t-test. Logistic regression analysis was applied to determine whether polymorphism of IL-6 and TIE2 affected the baseline peritoneal transport status. $p$ Values of $<0.05$ were considered statistically significant.

\section{RESULTS}

Clinical parameters between different transport groups

In total, 220 patients were enrolled in this study. The average age of the patients was $52.54 \pm 14.56$ years; the male-to-female ratio was 118:102 and the average body mass index was $21.83 \pm 3.47 \mathrm{~kg} / \mathrm{m}^{2}$. Residual renal function was $3.98 \pm 3.47 \mathrm{~mL} / \mathrm{min}$. The causes of ESRD were as follows: chronic glomerulonephritis $(\mathrm{n}=71$; $32.3 \%)$, diabetic nephropathy $(\mathrm{n}=32 ; 14.5 \%)$, hypertensive nephropathy $(\mathrm{n}=9 ; 4.1 \%)$ and other/unknown $(\mathrm{n}=107 ; 48.6 \%)$. Based on the first PET results, there were 97 patients $(44.1 \%)$ in the $\mathrm{H} / \mathrm{HA}$ group, and 123 patients $(55.9 \%)$ in the L/LA group. Comparisons of clinical characteristics between the two groups are shown in table 3 .

\section{Distribution of IL-6 and TIE2 polymorphisms in different transport groups}

The distributions of IL-6 and TIE2 genotypes in the peritoneal transport groups are summarised in tables 4 and 5. Distributions of the 24 alleles (12 polymorphisms) were within the Hardy-Weinberg equilibrium. For the IL-6 polymorphism, there was a statistically significant correlation between the AT genotype of rs13306435 and the peritoneal transport group $(\mathrm{p}=0.023)$. For the TIE2 polymorphism, the distribution of rs10967789 and

Table 3 Comparison of clinical characteristics and peritoneal parameters between the peritoneal transport groups of 220 patients with peritoneal dialysis

\begin{tabular}{|c|c|c|c|}
\hline & L/LA ( $n=123)$ & H/HA (n=97) & p Value \\
\hline Age (year) & $52.85 \pm 14.94$ & $52.27 \pm 14.42$ & 0.761 \\
\hline Male (\%) & $68(55.3)$ & $60(61.8)$ & 0.291 \\
\hline BMI $\left(\mathrm{kg} / \mathrm{m}^{2}\right)$ & $21.82 \pm 3.58$ & $21.85 \pm 3.03$ & 0.939 \\
\hline $\mathrm{DM}(\%)$ & $22(17.8)$ & $23(23.7)$ & 0.266 \\
\hline Hypertension (\%) & $94(68.1)$ & $75(70.1)$ & 0.740 \\
\hline Periods between operation and initial PET (d) & $48(39,69)$ & $47(35,68)$ & 0.924 \\
\hline Haemoglobin $(g / L)$ & $104.60 \pm 22.67$ & $99.13 \pm 21.29$ & 0.056 \\
\hline Serum albumin ( $g / L)$ & $36.37 \pm 4.7$ & $34.8 \pm 5.33$ & 0.017 \\
\hline hs-CRP (mg/L) & $2.65(0.71,3.83)$ & $2.58(1,3.86)$ & 0.657 \\
\hline ACEI/ARB (\%) & $64(52)$ & $53(54.6)$ & 0.624 \\
\hline D4/D0 (glucose) & $0.44 \pm 0.08$ & $0.34 \pm 0.08$ & $<0.01$ \\
\hline $\mathrm{D} / \mathrm{P} \mathrm{Cr}$ & $0.55 \pm 0.08$ & $0.74 \pm 0.07$ & $<0.01$ \\
\hline $\mathrm{RRF}(\mathrm{mL} / \mathrm{min})$ & $4 \pm 2.92$ & $3.95 \pm 2.63$ & 0.901 \\
\hline $\operatorname{Npcr}(g /(k g . d))$ & $1.05 \pm 0.6$ & $0.96 \pm 0.26$ & \\
\hline UF (mL) & $160(-200,520)$ & $80(-45,500)$ & 0.004 \\
\hline Urine volume (mL) & $1000(560,1400)$ & $1000(500,1500)$ & 0.217 \\
\hline $\mathrm{Kt} / \mathrm{V}$ & $2.23 \pm 0.58$ & $2.20 \pm 0.56$ & 0.647 \\
\hline
\end{tabular}

ACEI; ACE inhibitors; ARB, angiotensin-receptor blockers; BMI, body mass index; DM, diabetes mellitus; D/P Cr, dialysate over plasma ratio for creatinine; $\mathrm{H}$, high; HA, high average; hs-CRP, high-sensitive $\mathrm{C}$ reactive protein; L, low; LA, low average; PET, peritoneal equilibration test; RRF, residual renal function; UF, ultrafiltration. 
Table 4 IL-6 gene polymorphisms in two groups

\begin{tabular}{|c|c|c|c|}
\hline & L/LA (n=123) & H/HA (n=97) & p Value \\
\hline \multicolumn{4}{|c|}{ Rs13306435 } \\
\hline AT & 14 & 3 & 0.023 \\
\hline TT & 109 & 94 & \\
\hline \multicolumn{4}{|c|}{ Rs1800796 } \\
\hline $\mathrm{CC}$ & 77 & 61 & 0.986 \\
\hline CG & 37 & 28 & \\
\hline GG & 9 & 8 & \\
\hline \multicolumn{4}{|c|}{ Rs1800795 } \\
\hline GG & 121 & 96 & 0.506 \\
\hline GC & 2 & 1 & \\
\hline
\end{tabular}

IL, interleukin; H, high; HA, high average; L, low; LA, low average. rs10967789 and rs639225). We found no statistically significant difference in the data of $\mathrm{D} / \mathrm{P} \mathrm{Cr}$ and $\mathrm{D} / \mathrm{D} 0$ glucose (the ratio of dialysate glucose concentrations at 0 and 4 hours) among different genotypes (table 6).

\section{Roles of IL-6 and TIE2 gene polymorphisms in predicting} initial peritoneal high transport status

With possible clinical factors controlled in a multiple logistic regression model, the genotype AT in IL-6 Rs13306435 and CC in TIE2 Rs639225 were both negatively associated with a higher initial peritoneal transport status (IL-6 Rs13306435: OR=0.408, 95\% CI 0.227 to 0.736; TIE2 Rs639225: OR $=0.188,95 \%$ CI 0.044 to 0.806 ; table 7).

Table 5 TIE2 gene polymorphisms in two groups

\begin{tabular}{|c|c|c|c|}
\hline & L/LA (n=123) & H/HA (n=97) & p Value \\
\hline \multicolumn{4}{|c|}{ Rs10967717 } \\
\hline AA & 15 & 16 & \multirow[t]{3}{*}{0.652} \\
\hline$A G$ & 56 & 47 & \\
\hline GG & 52 & 34 & \\
\hline \multicolumn{4}{|c|}{ Rs10967789 } \\
\hline $\mathrm{CC}$ & 90 & 83 & \multirow[t]{2}{*}{0.039} \\
\hline CG & 33 & 14 & \\
\hline \multicolumn{4}{|c|}{ Rs2273718 } \\
\hline$A G$ & 14 & 4 & \multirow[t]{2}{*}{0.081} \\
\hline GG & 109 & 93 & \\
\hline \multicolumn{4}{|c|}{ Rs2273719 } \\
\hline AA & 4 & 2 & \multirow[t]{3}{*}{0.868} \\
\hline$A G$ & 36 & 27 & \\
\hline GG & 83 & 68 & \\
\hline \multicolumn{4}{|c|}{ Rs3737188 } \\
\hline $\mathrm{CC}$ & 6 & 1 & \multirow[t]{3}{*}{0.373} \\
\hline CT & 44 & 31 & \\
\hline $\mathrm{TT}$ & 73 & 65 & \\
\hline \multicolumn{4}{|c|}{ Rs542913 } \\
\hline $\mathrm{CC}$ & 100 & 80 & \multirow[t]{3}{*}{0.403} \\
\hline CT & 22 & 17 & \\
\hline $\mathrm{TT}$ & 1 & 0 & \\
\hline \multicolumn{4}{|c|}{ Rs639225 } \\
\hline $\mathrm{CC}$ & 40 & 18 & \multirow[t]{3}{*}{0.047} \\
\hline CT & 53 & 46 & \\
\hline $\mathrm{TT}$ & 30 & 33 & \\
\hline \multicolumn{4}{|c|}{ Rs657867 } \\
\hline AA & 112 & 87 & \multirow[t]{2}{*}{0.732} \\
\hline$A G$ & 11 & 10 & \\
\hline \multicolumn{4}{|c|}{ Rs9987817 } \\
\hline $\mathrm{CC}$ & 97 & 74 & \multirow[t]{3}{*}{0.730} \\
\hline CT & 22 & 22 & \\
\hline $\mathrm{TT}$ & 4 & 1 & \\
\hline
\end{tabular}

rs639225 genotypes differed significantly between the two groups ( $p=0.039$ and 0.047 , respectively).

\section{Parameters for peritoneal solute transport rate for} different genotypes

We further compared the peritoneal solute transport rate among groups with the three SNPs (rs13306435,

\section{DISCUSSION}

The relationship between gene polymorphisms and disease has been receiving greater attention from researchers. It has been shown that SNPs of IL-6 may influence the development of cardiovascular disease, ${ }^{28}$ cancer, ${ }^{29}{ }^{30}$ fractures ${ }^{31}$ and autoimmune diseases. ${ }^{32-34}$ In contrast, there is less available research regarding TIE2 gene polymorphisms, except for a study on the relationship between rs638203/rs639225 and vascular malformations. ${ }^{35}$

In this study, we investigated the effect of genetic polymorphisms of IL-6 and TIE2 on the baseline peritoneal transport property. Results showed that IL-6 and TIE2 gene polymorphisms were both negatively associated with initial high transport status. The genotypes of rs13306435 and rs639225 were shown to be independent predictors of initial high transport status in patients with PD.

Initial transport status can determine the patients' dialysis prescription, which may influence the outcome for patients with PD. Previous studies have shown an association between initial high transport status and poor outcome. Although icodextrin and APD have been shown to improve the prognosis of high transporters, most of the patients with PD in developing countries are unable to use them. In China, for instance, icodextrin has not been approved for sale yet, and few patients can afford the cost of APD therapy. Therefore, predicting

Table 6 The parameters for peritoneal solute transport rate according to different genotypes

\begin{tabular}{llll}
\hline IL-6 Rs13306435 & AT & TT & p Value \\
\hline D/P creatinine & $0.61 \pm 0.99$ & $0.63 \pm 0.12$ & 0.357 \\
D/D0 glucose & $0.41 \pm 0.092$ & $0.39 \pm 0.085$ & 0.424 \\
TIE2 Rs639225 & CC & CT/TT & \\
D/P creatinine & $0.61 \pm 0.11$ & $0.64 \pm 0.11$ & 0.056 \\
D/D0 glucose & $0.40 \pm 0.09$ & $0.39 \pm 0.08$ & 0.518 \\
TIE2 Rs10967789 & $\mathrm{CC}$ & $\mathrm{CG}$ & \\
D/P creatinine & $0.64 \pm 0.12$ & $0.61 \pm 0.09$ & 0.187 \\
D/D0 glucose & $0.39 \pm 0.09$ & $0.40 \pm 0.06$ & 0.839 \\
\hline D/P, dialysate over plasma ratio; IL, interleukin. &
\end{tabular}


Table 7 Multivariate logistic regression model to identify factors associated with high/high average transport status

\begin{tabular}{llll}
\hline & OR & $\mathbf{9 5 \%} \mathbf{C l}$ & $\mathbf{p ~ V a l u e ~}$ \\
\hline TIE2 Rs639225 (CC vs CT/TT) & 0.188 & 0.044 to 0.806 & 0.024 \\
IL-6 Rs13306435 (AT vs TT) & 0.408 & 0.227 to 0.736 & 0.043 \\
Age & 0.966 & 0.930 to 1.004 & 0.081 \\
Male & 1.401 & 0.519 to 3.788 & 0.506 \\
DM & 3.28 & 0.952 to 11.360 & 0.060 \\
Periods between operation and initial PET (d) & 0.996 & 0.987 to 1.005 & 0.401 \\
hs-CRP(mg/L) & 1.081 & 0.964 to 1.212 & 0.182 \\
Serum albumin (g/L) & 0.898 & 0.796 to 1.014 & 0.083 \\
TIE2 Rs10967789 (CC vs CG) & 1.061 & 0.371 to 1.632 & 0.197 \\
Haemoglobin (g/L) & 0.984 & 0.796 to 1.014 & 0.192 \\
\hline DM, diabetes mellitus; hs-CRP, high-sensitive C reactive protein; IL, interleukin; PET, peritoneal equilibration test.
\end{tabular}

the baseline transport status is important to select a better treatment strategy. Our study provided a potential solution to predict initial high transport status before beginning PD.

There have been several genetic studies of peritoneal solute transport rate in patients with PD. Polymorphisms of endothelial nitric oxide synthase, ${ }^{16}$ receptor of advanced glycation end products ${ }^{17}$ and transforming growth factor- $\beta 1^{18}$ were reported to be involved in baseline transport status. In 2005, Gillerot et $a l^{15}$ showed that the SNP of IL-6 (rs1800795) influenced baseline peritoneal permeability in Caucasian patients with PD. Additionally, Hwang et $a l^{19}$ reported that the rs1800795 polymorphism was associated with dialysate IL-6 concentration and baseline peritoneal transport status in Korean patients with PD. However, for the Chinese Han population, the minor allele frequency (MAF) of rs1800795 was reported to be very low $(\mathrm{MAF}=0.02)$. Thus, it might not be appropriate to directly apply these results to this population. Our finding is similar to those of the aforementioned studies. This supports the role of the IL-6 polymorphism in predicting baseline peritoneal transport.

Angiogenesis in the peritoneum could directly increase the effective solute exchange area and influence the transport characteristics. Previous studies have found that polymorphisms of vascular endothelial growth factor were not associated with initial peritoneal transport type. ${ }^{15} 17$ Ang/Tie2 has recently been confirmed to play an important role in angiogenesis in the peritoneum. ${ }^{26}$ Whether the polymorphisms of TIE2 are involved in initial peritoneal transport status remains unknown. In this study, we carefully selected nine SNPs with $\mathrm{MAF}>0.05$ in the Chinese Han population to investigate their possible role in predicting high transport status. The results showed that TIE2 could be a new factor in predicting the baseline transport type. This is the first study to explore the possible association between TIE2 gene polymorphisms and characteristics of peritoneal transport. Rs639225 is located in exon 13 of TIE2. A study reported its association with venous malformation and presumed that this polymorphism might cause abnormal splicing of TIE2 into a defective protein. ${ }^{28}$ Functional validation of this polymorphism is warranted in the future.

There are some limitations to our study. The TA genotype of rs13306435 presents in only $7 \%$ of the total population; therefore, it is not the main determinant of peritoneal transport in most patients. Additionally, this study was conducted at a single centre and the number of cases was limited; increasing the sample size would improve this study. Research has shown that the IL-6/ TIE2 concentration was associated with baseline transport status. We hypothesised that the SNPs may participate in the formation of high transport status by influencing the dialysate IL-6/TIE2 concentration. We did not examine the dialysate IL-6/TIE2 concentration in this study. As shown in table 6, we did not find any statistically significant difference in the data of $\mathrm{D} / \mathrm{P} \mathrm{Cr}$ and D/D0 glucose between the different genotypes. We believe that this may be due to the limited sample size.

In conclusion, IL-6 and TIE2 polymorphisms are associated with baseline peritoneal transport property. A functional study of the polymorphisms is required in the future.

Contributors LD, XS and ZN contributed to conception and design. LD, $X S$, LC, WF, HY, JH, AG, ZY, CQ, XC and ZN contributed to acquisition of data, or analysis and interpretation of data. LD, XS, LC, WF, HY, JH, AG, $Z Y, C Q, X C$ and $Z N$ contributed to drafting the manuscript or revising it critically for important intellectual content. All authors reviewed the manuscript.

Funding This work was supported by the National Basic Research Program of China 973 Program (2012CB517602), National 'Twelfth Five-Year' Plan for Science \&Technology (2011BAl10B08), the Shanghai Science and Technology Committee (10JC1410100).

Competing interests None declared.

Patient consent Obtained.

Ethics approval Ethical committee of Renji Hospital, School of Medicine, Shanghai Jiao Tong University, Shanghai 200127, China.

Data sharing statement The technical appendix, statistical code and data set are available from the corresponding author.

Open Access This is an Open Access article distributed in accordance with the Creative Commons Attribution Non Commercial (CC BY-NC 4.0) license, which permits others to distribute, remix, adapt, build upon this work noncommercially, and license their derivative works on different terms, provided 
the original work is properly cited and the use is non-commercial. See: http:// creativecommons.org/licenses/by-nc/4.0/

\section{REFERENCES}

1. Cueto-Manzano AM. Rapid solute transport in the peritoneum: physiologic and clinical consequences. Perit Dial Int 2009;29(Suppl 2):S90-5.

2. Twardowski ZJ, Nolph KDA, Khanna R, et al. Peritoneal equilibration test. Perit Dial Bull 1987;7:138-47.

3. Churchill DN, Thorpe KE, Nolph KD. Increased peritoneal membrane transport is associated with decreased patient and technique survival for continuous peritoneal dialysis patients. The Canada-USA (CANUSA) Peritoneal Dialysis Study Group. J Am Soc Nephrol 1998;9:1285-92.

4. Rumpsfeld M, McDonald SP, Johnson DW. Higher peritoneal transport status is associated with higher mortality and technique failure in the Australian and New Zealand peritoneal dialysis patient populations. J Am Soc Nephrol 2006;17:271-8.

5. Chung SH, Heimbürger $\mathrm{O}$, Lindholm $\mathrm{B}$. Poor outcomes for fast transporters on PD: the rise and fall of a clinical concern. Semin Dial 2008;21:7-10.

6. Janda K, Krzanowski M, Dumnicka P, et al. Peritoneal solute transport rate as an independent risk factor for total and cardiovascular mortality in a population of peritoneal dialysis patients. Adv Perit Dial 2014;30:15-20.

7. Brimble KS, Walker M, Margetts PJ, et al. Meta-analysis: peritoneal membrane transport, mortality, and technique failure in peritoneal dialysis. J Am Soc Nephrol 2006;17:2591-8.

8. Ahn SV, Vonesh E, Han SH. Survival advantage of icodextrin peritoneal dialysis solution in a time-dependent model. Am J Kidney Dis 2013;61:351-2.

9. Oba I, Shinozaki M, Harada K, et al. Icodextrin-based continuous ambulatory peritoneal dialysis therapy effectively reduces left ventricular mass index and protects cardiac function in patients with end-stage renal disease. Adv Perit Dial 2013;29:14-18.

10. Yoon HE, Chang YK, Shin SJ, et al. Benefits of a continuous ambulatory peritoneal dialysis (CAPD) technique with one icodextrin-containing and two biocompatible glucose-containing dialysates for preservation of residual renal function and biocompatibility in incident CAPD patients. J Korean Med Sci 2014;29:1217-25.

11. Wang IK, Li YF, Chen JH, et al. Icodextrin decreases technique failure and improves patient survival in peritoneal dialysis patients. Nephrology (Carlton) 2015;20:161-7.

12. Chang TI, Park JT, Lee DH, et al. High peritoneal transport status is not an independent risk factor for high mortality in patients treated with automated peritoneal dialysis. J Korean Med Sci 2010;25:1313-17.

13. Cnossen TT, Usvyat L, Kotanko P, et al. Comparison of outcomes on continuous ambulatory peritoneal dialysis versus automated peritoneal dialysis: results from a USA database. Perit Dial Int 2011;31:679-84.

14. Lan PG, Johnson DW, McDonald SP, et al. The association between peritoneal dialysis modality and peritonitis. Clin J Am Soc Nephrol 2014;9:1091-7.

15. Gillerot G, Goffin E, Michel C, et al. Genetic and clinical factors influence the baseline permeability of the peritoneal membrane. Kidney Int 2005;67:2477-87.

16. Akcay A, Micozkadioglu H, Atac FB, et al. Relationship of ENOS and RAS gene polymorphisms to initial peritoneal transport status in peritoneal dialysis patients. Nephron Clin Pract 2006;104:c41-6.
17. Maruyama $\mathrm{Y}$, Numata $\mathrm{M}$, Nakayama $\mathrm{M}$, et al. Relationship between the -374T/A receptor of advanced glycation end products gene polymorphism and peritoneal solute transport status at the initiation of peritoneal dialysis. Ther Apher Dial 2007;11:301-5

18. Ebinç FA, Derici U, Gönen S, et al. TGF-beta1 gene polymorphisms and peritoneal equilibration test results in CAPD patients. Ren Fail 2008;30:15-19.

19. Hwang $\mathrm{YH}$, Son MJ, Yang J, et al. Effects of interleukin-6 T15A single nucleotide polymorphism on baseline peritoneal solute transport rate in incident peritoneal dialysis patients. Perit Dial Int 2009;29:81-8.

20. Lee YT, Tsai YC, Yang YK, et al. Association between interleukin-10 gene polymorphism $-592(\mathrm{~A} / \mathrm{C})$ and peritoneal transport in patients undergoing peritoneal dialysis. Nephrology (Carlton) 2011;16:663-71.

21. Cruz DN, Soni SS, Polanco N, et al. Markers of inflammation and oxidative stress in peritoneal dialysis: a comparison between high and low peritoneal transporters. J Nephrol 2010;23:453-8.

22. Pecoits-Filho R, Araújo MR, Lindholm B, et al. Plasma and dialysate IL-6 and VEGF concentrations are associated with high peritoneal solute transport rate. Nephrol Dial Transplant 2002;17:1480-6.

23. Verduijn M, Maréchal C, Coester AM, et al. The $-174 \mathrm{G} / \mathrm{C}$ variant of IL6 as risk factor for mortality and technique failure in a large cohort of peritoneal dialysis patients. Nephrol Dial Transplant 2012;27:3516-23.

24. Cho Y, Johnson DW, Vesey DA, et al. Dialysate interleukin-6 predicts increasing peritoneal solute transport rate in incident peritoneal dialysis patients. BMC Nephrol 2014;15:8.

25. Numata M, Nakayama M, Nimura S, et al. Association between an increased surface area of peritoneal microvessels and a high peritoneal solute transport rate. Perit Dial Int 2003;23:116-22.

26. Yuan J, Fang W, Ni Z, et al. Peritoneal morphologic changes in a peritoneal dialysis rat model correlate with angiopoietin/Tie-2. Pediatr Nephrol 2009;24:163-70.

27. Xiao J, Guo J, Liu XX, et al. Soluble Tie2 fusion protein decreases peritoneal angiogenesis in uremic rats. Mol Med Rep 2013;8:267-71.

28. Han YH. Association between IL6 polymorphism and risk of cerebral infarction. Genet Mol Res 2015;14:16438-43.

29. Du Y, Gao L, Zhang K et al. Association of the IL6 polymorphism rs1800796 with cancer risk: a meta-analysis. Genet Mol Res 2015;14:13236-46.

30. Gautam KA, Muktanand T, Sankhwar SN, et al. Functional polymorphisms in the IL6 gene promoter and the risk of urinary bladder cancer in India. Cytokine 2016;77:152-6.

31. Zhang Z, He N, Zhang T. IL6-174G/C polymorphism and fracture risk. Int J Clin Exp Med 2014;7:3795-9.

32. Čengić T, Trkulja V, Pavelić SK, et al. Association of TGFB1 29C/T and IL6 $-572 \mathrm{G} / \mathrm{C}$ polymorphisms with developmental hip dysplasia: a case-control study in adults with severe osteoarthritis. Int Orthop 2015:39:793-8.

33. Durães C, Moreira CS, Alvelos I, et al. Polymorphisms in the TNFA and IL6 genes represent risk factors for autoimmune thyroid disease. PLOS ONE 2014;9:e105492.

34. Ururahy MA, de Souza KS, Oliveira YM, et al. Association of polymorphisms in IL6 gene promoter region with type 1 diabetes and increased albumin-to-creatinine ratio. Diabetes Metab Res Rev 2015;31:500-6.

35. Zheng Q, Du J, Zhang Z, et al. Association study between of Tie2/ angiopoietin-2 and VEGF/KDR pathway gene polymorphisms and vascular malformations. Gene 2013;523:195-8. 